\title{
In Reply to "Impact of the Psychiatry Clerkship on Medical Student Attitudes Towards Psychiatry and to Psychiatry as a Career"
}

\author{
Gábor Gazdag • Gabor S. Ungvari
}

Received: 9 November 2014 / Accepted: 27 November 2014 / Published online: 15 January 2015

(C) Academic Psychiatry 2015

To the Editor:

We have read with great interest Lyons' paper [1] about the impact of psychiatric clerkship on medical students' attitudes toward psychiatry in general and to psychiatry as a career. In 2006, our research group conducted a similar attitude survey in medical students during their psychiatry clerkship. The results of this study were published in English in a local journal, Psychiatria Hungarica, and its abstract can be found on PubMed [2]. Because our paper was not included in Lyons' review, we would like to draw attention to our work to broaden the international perspective of this important topic. Our study targeted 5th-year medical students, who had $2 \mathrm{~h}$ of psychiatry practice weekly throughout the year. We used the ATP-30 [3] to assess students' attitudes. In comparison with other studies, the response rate of our Hungarian study was relative low, only $24 \%$; students' attitudes were relatively positive toward psychiatry at the beginning of the clerkship, but scores only minimally increased during the year. Our findings contrast with the finding of Lyons' review of improvement in attitudes in $61 \%$ of the studies. Even more intriguing was our finding that psychiatry became less attractive following the clerkship, as evidenced by the significant drop in the score for the statement "I would like to be a psychiatrist." In Lyons' review, $50 \%$ of the studies detected a positive impact of psychiatry clerkship on medical students' career choice. The critically low number of Hungarian medical students willing to enter the psychiatric workforce calls for strategies to improve the reputation of psychiatry in Hungary.

\section{References}

1. Lyons Z. Impact of the psychiatry clerkship on medical student attitudes towards psychiatry and to psychiatry as a career. Acad Psychiatry. 2014;38:35-42.

2. Gazdag G, Zsargó E, Vukov P, Ungvari GS, Tolna J. Change of medical student attitudes toward psychiatry: the impact of the psychiatric clerkship. Psychiatr Hung. 2009;24:248-54.

3. Burra P, Kalin R, Leichner P, Waldron JJ, Handforth JR, Jarrett FJ, et al. The ATP 30 - a scale for measuring medical students' attitudes to psychiatry. Med Educ. 1982;16:31-8.
G. Gazdag $(\bowtie)$

Szent István and Szent László Hospitals, Budapest, Hungary

e-mail: gazdag@lamb.hu

\section{G. S. Ungvari}

University of Notre Dame/Marian Centre, Perth, Australia 